\title{
Narcissus, the beam and lung cancer: What is the message?
}

\author{
Gail E. Darling, MD, FRCSC, FACS
}

\author{
From the Division of Thoracic Surgery, Department of Surgery, University of Toronto, Toronto, Ontario, Canada. \\ Disclosures: Author has nothing to disclose with regard to commercial support. \\ Received for publication May 11, 2016; accepted for publication May 19, 2016. \\ Address for reprints: Gail E. Darling, MD, FRCSC, FACS, Toronto General Hospital, University Health Network, \\ 200 Elizabeth St 9N-955, Toronto, Ontario, Canada M5G 2C4 (E-mail: gail.darling@uhn.ca). \\ J Thorac Cardiovasc Surg 2016;152:344 \\ $0022-5223 / \$ 36.00$ \\ Copyright (c) 2016 Published by Elsevier Inc. on behalf of The American Association for Thoracic Surgery \\ http://dx.doi.org/10.1016/j.jtcvs.2016.05.028
}

Dr Rocco, ${ }^{1}$ in this issue of the Journal, has written an eloquent and thought-provoking article ("Narcissus, the Beam and Lung Cancer") that reminds us of the importance of patient values and the ever evolving practice of medicine. Those who don't move forward will be left behind.

New technologies will always come along and will find their place in patient care. These innovative approaches most often are less invasive with less morbidity and mortality and improved health-related quality of life. In the case of stereotactic body radiation therapy (SBRT) for lung cancer, there is no pain, no incision(s), no hospitalization, no risk of procedure-related mortality, and minimal inconvenience in terms of time off work or away from home (Figure 1). Who wouldn't choose SBRT as treatment for their lung cancer? As surgeons, we argue that there is no level 1 evidence proving that SBRT is as good as surgery. We argue that the tumor will not be adequately staged because lymph nodes will not be biopsied. (But do we biopsy lymph nodes when we do a wedge resection?) We argue that there is no long-term follow-up. We may feel threatened by the competition for patients with a disease for which we have always dominated.

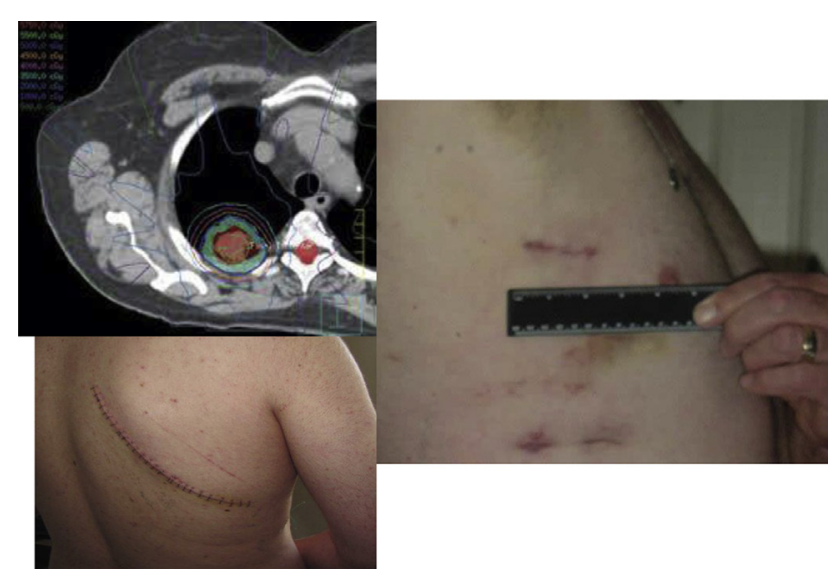

FIGURE 1. Top, A stereotactic body radiation plan; bottom left, posterolateral thoracotomy; center right, video-assisted thoracoscopic surgery lobectomy incisions. certain.

\section{Reference} 152:338-43.e3.

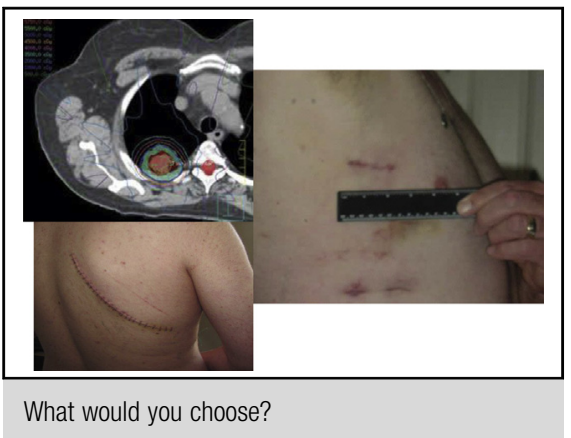

Central Message

Thoracic surgeons must embrace innovation, carefully evaluate new technologies, and remain experts in the diseases they treat so that they can best advise patients regarding treatment choices.

See Article page 338 .

Although it is true that there is no level 2 evidence that SBRT is as good as surgery, we surgeons have contributed to the lack of evidence by not participating in appropriately designed randomized trials. A new randomized trial is now open and enrolling. We owe it to ourselves, our radiation oncology colleagues, and our patients to participate in this new trial so that we can establish the evidence we seek. In the end, we have to do what is best for the patient and consider their values in making treatment recommendations. There will always be patients who choose a less-painful, less-invasive but more convenient treatment even if the long-term outcome is less

Dr Robert Ginsberg told me that if I wanted to treat lung cancer I had to know the literature, not just surgical literature but medical and radiation oncology literature and everything to do with lung cancer. Thoracic surgeons have been the experts in lung cancer, from diagnosis to staging to treatment. If we want to continue in this role, we must remain the experts with knowledge of the biology, the clinical and radiologic features, and all treatment options. If we do this, we will be in the best position to advise the patient about treatment, and not just the technician who cuts out the cancer.

1. Rocco G. Narcissus, the beam and lung cancer. J Thorac Cardiovasc Surg. 2016; 